gave rise to suspicion. The second category would be restricted to all sudden deaths in subjects over a certain age (around 40) in which there were no suspicious or complicating circumstances. A proportion of these, say $5 \%$, would be selected randomly for full necropsy; the results would be the basis of a statistical analysis of the cause of death of the group as a whole. The remaining $95 \%$ of cases would be subjected to detailed external examination by a qualified pathologist. Should any significant abnormality be discovered-for example, petechial haemorrhages suggesting death by suffocation-the case would be recategorized into group 1 and a full necropsy performed. If no external abnormalities were present samples of stomach contents and a wedge of liver tissue could be rapidly obtained by the mortuary technician and submitted for toxicological screening at a forensic science laboratory. If a well-organized national system was adopted there is no reason why such tests should not be automated and take only a few days. In the interim burial would be possible but cremation would await clearance by the toxioological laboratory.

The potential reduction in the number of coroners' necropsies by this method would be very considerable in the country as a whole.-I am, etc.

Milton, Cambridge

PATRICK Gallagher

\section{Azathioprine in Psoriasis}

SIR,-Following the report of azathioprine in the treatment of psoriasis by Dr. A. du Vivier and others (12 January, p. 49) thought it would be of interest to report the possible myopathic effect of azathioprine in this disease. Myopathy is not uncommon in renal transplant patients on both azathioprine and prednisone ${ }^{1}$ but myopathy due to azathioprine alone has rarely been reported.

A 62-year-old man who had had psoriasis for 16 years developed exfoliative dermatitis three months before a course of azathioprine. Systemic methotrexate had been stopped because of haemorrhagic cystitis. After a month on azathioprine $200 \mathrm{mg}$ daily $(2 \cdot 4 \mathrm{mg} / \mathrm{kg})$ he developed progressive daily $(2 \cdot 4 \mathrm{mg} / \mathrm{kg})$ he developed progressive Theakness of the legs and difficulty in walking. There was marked grade 4 weakness of the deltoids similar weakness of the proximal leg muscles with depressed knee jerks, absent ankle jerks, and flexor plantar responses. The muscles were no tender and there was minimal wasting. There was no clinical evidence of peripheral neuropathy and the clinical impression of myopathy was confirmed on electromyography. At this time the patient was putting about $80 \mathrm{~g}$ clobetasol propionate $0.05 \%$ ointment daily on to his skin without occlusion. After stopping azathioprine and changing the After stopping azathioprine and changing the $0.1 \%$ diluted 10 times, muscle strength returned $0.1 \%$ diluted 10 times, muscle
to normal within three weeks.

Systemic absorption of local fluorinated steroids has not previously been reported to produce myopathy and it seems likely that in this patient azathioprine alone produced the myopathy.-I am, etc.,

R. Clayton

Skin Department,

London $\mathrm{W} .2$

1 British Medical fournal, 1966, 2, 1378.

\section{Battering: Unfortunate Backlash}

SIR,-Having for some years been oncerned with battering parents and those suspected of abusing their child, I agree wholeheartedly with Dr. J. W. Woodward's letter (9 March, p. 452). Several instances known to me illustrate that after much initial reluctance to recognize the syndrome there may now be a real danger of hasty and insensitive steps being taken against innocen parents by workers who act, or are asked to act, on uncorroborated assumptions.

The problem contains other elements than those of careful diagnosis and investigation. It happens that all too often both confirmed and suspected cases are not handled with the skill that is required if the aim of the intervention is to improve the parent-child relationship and not just to achieve some spurious short-term "protection" of the baby. In order to be able to help effectively workers require special training and a better understanding of the reasons why even loving mothers are driven to harm their baby.

It has to be appreciated that battering is no an unrelated component of behaviour, and it cannot therefore be evaluated and treated in isolation. The syndrome is only one manifestation of a whole complex of interrelated and not uncommon conflicts both in women and men who find it difficult to adjust to their role as parents. Many of the women who feel inadequate in face of their maternal responsibility deal with this by avoiding close contact with their baby in an attemp to protect it from their aggression. The vulnerability and the special emotional problems of the fundamentally insecure mother require that she be approached in a way which does not undermine her already weak confidence and self-esteem. Above all, nothing must be said or done to imply even the slightest suspicion of child abuse unti there is irrefutable evidence of it. The merest hint of such a suspicion is bound to be sensed by the innocent mother as a sign that her maternal adequacy is doubted, and this happens at the precise moment when she needs encouragement and support. By not focusing on the issue of battering but by attempting to cope with problems and their roots in the context of the wider spectrum of the parent-infant relationship the danger of causing irreparable harm to emotionally vulnerable families is avoided.

Whatever form the management of such cases take, it should be based on the recognition that battering is only one form of child abuse and that the scars of emotional abuse, for which there should be an equal measure of concern from the helping professions, are no less crippling to the child. -I am, etc.

Hampstead Child-therapy Clinic

BIANCA GORDON

Hampstead Child

\section{Parents of Battered Babies}

Sir,-Dr. J. K. Sarsfield and Mr. A. C Dowell (30 March, p. 637) are quite correct in their assertion that anomalies of family status have a bearing on the circumstances leading to baby battering. Our results on this are to be published in detail elsewhere, but the importance of the points Dr. Sarsfield and Mr. Dowell raise merits immediate comment.

In our sample lack of family cohesiveness was an important precursor of baby battering. In over one-third of cases the biological father was absent from home and in half the mothers were living with some other man.
Half the mothers had married before the age of 20 years and nearly three-quarters had conceived premaritally-a combination particularly likely to lead to marital breakdown. ${ }^{2}$ Such mothers also had strikingly more premarital pregnancies and illegitimate births when compared with the general population, suggesting that the inconvenience of an unwanted child was an important motive underlying baby battering. Short acquaintance before marriage, disharmony in child rearing, and dissatisfaction with their partner's handling of the child were other predictors of divorce ${ }^{3}$ found in our sample. These parents also had little contact with their own parents and relatives and thus lacked the stabilizing force of a kinship relationship." Considering that a significant proportion of our parents suffered all these marital adversities and that one-third of battered babies were already living with one natural parent only it may be predicted that a substantial number of such children will eventually grow up in broken homes and be at risk of social maldevelopment and physical, and possibly fatal, injury.

Because the similarities between baby battering and other forms of deviant behaviour are striking ${ }^{1}$ and because innumerable studies of deviant behaviour have been remarkably unrewarding, not only in establishing causes but also treatment, it is my contention that if doctors are to prevent rebattering then this is one area where they must be authoritative, intrusive, and insistent. As with crime and delinquency, treatment is likely to be only a supporting exercise. True prevention must lie in the effective education of the next generation and in possible legal changes in child care. -I am, etc.,

SELWYN M. SMITH

Department of Psychiatry,

Queen Eliza

1 Smith, S. M., Hanson, R., and Noble, S. British fournal of Psychiatry. In press.

2 Rowntree, G., Population Studies, 1964, 18, 147. Goode, W. J., in Sociology of the Family, ed. M Anderson, p. 301. Harmondsworth, Penguin Books, 1971 de Lissovoy, V., fournal of Marriage and the

\section{Coxsackie B Virus and Diabetes}

SIR,-Dr. D. R. Gamble and others (3 November 1973, p. 260) recently reported the association of positive titre levels for Coxsackie B4 virus and diabetes mellitus, supporting their earlier findings. ${ }^{12}$ The significant association was in the $10-$ to 19 year-old subjects. The incidence of positive titres is high in the population they studied, and since from their data the onset of infection and the onset of diabetes cannot b: analysed no cause and effect relationship can be deduced. A true association of onset of infection, persistence of titre levels, and onset of diabetes could be evaluated in a community without prior exposure to the virus which suffered an epidemic, as Hadden and others suggested. ${ }^{3}$

We recently studied such a community on the Pribolof Islands in Alaska, U.S.A. In the winter of 1967-8 an epidemic caused by Coxsackie B4 occurred in a previously unexposed population, as determined by preepidemic sera. Of the 116 persons with available pre-epidemic sera only two had positive neutralizing antibody titres (1:4, 